\title{
Nanoemulsion Improves Antinociceptive Activity of HP1, a Benzopyran from Hypericum polyanthemum
}

\section{다 (i) $(9)$}

\author{
Authors \\ Gabriela Meirelles, Henrique Bridi, Eveline Dischkaln Stolz, Helder Ferreira Teixeira, Gilsane Lino von Poser, Stela Maris \\ Kuze Rates
}

\author{
Affiliation \\ Pharmaceutical Sciences Postgraduate Program, Federal \\ University of Rio Grande do Sul, Porto Alegre, Brazil
}

\section{Key words}

Hypericum polyanthemum, Hypericaceae, antinociceptive, HP1, nanoemulsion

$\begin{array}{ll}\text { received } & 10.04 .2017 \\ \text { revised } & 31.07 .2017 \\ \text { accepted } & 04.09 .2017\end{array}$

\section{Bibliography}

DOI https://doi.org/10.1055/s-0043-119759

Planta Med Int Open 2017; 4: e82-e88

(c) Georg Thieme Verlag KG Stuttgart · New York ISSN 2509-9264

\section{Correspondence}

Prof. Dr. Gilsane Lino von Poser

Post Graduate Program in Pharmaceutical Sciences

Pharmacy Faculty

Federal University of Rio Grande do Sul

Porto Alegre

Brazil

Tel.: + 55/51/3308 5289

gilsane@farmacia.ufrgs.br

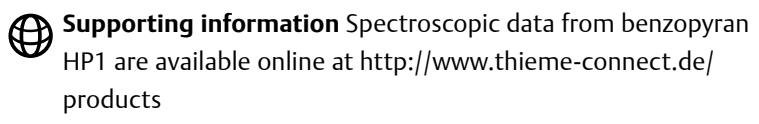

\begin{abstract}
The impact of nanoemulsification on the antinociceptive effect of benzopyran HP1 in a mice hot plate test was investigated. For comparison, the same experiments were performed with HP1-free form. The durability of the antinociceptive effect was analyzed at 60,120 and $180 \mathrm{~min}$. The results revealed that HP1 was successfully incorporated into a nanoemulsion system, given its high solubility in the oil phase. Regarding the pharmacological effect, HP1 (15, 30, 45, and $60 \mathrm{mg} / \mathrm{kg}$, p.o.), both forms, displayed the pattern of a bell-shaped dose-response curve. HP1-loaded nanoemulsion displayed the maximal antinociceptive effect at a lower dose than the HP1-free form. The highest effect of the free compound was observed at $45 \mathrm{mg} /$ $\mathrm{kg}$, while the HP1-loaded nanoemulsion displayed the same effect at $30 \mathrm{mg} / \mathrm{kg}$. These results suggest that the observed effect might be attributable to an increase in solubility and, thus, the enhancement of compound absorption. Regarding the durability of the antinociceptive effect, the outcomes demonstrated that the HP1-free form lost its antinociceptive effect at $120 \mathrm{~min}$, while the HP1-loaded nanoemulsion kept its effect until $180 \mathrm{~min}$. These findings corroborate literature data, where studies have demonstrated absorption enhancement when a compound was loaded in a nanoemulsion system.
\end{abstract}

\section{Introduction}

The International Association for the Study of Pain (IASP) defines pain as an "unpleasant sensory and emotional experience associated with actual or potential tissue damage" [1]. Pain is considered a major clinical, social, and economic problem in populations around the world [2]. Moreover, it is the defining feature for the diagnoses of several diseases and can serve as an index of severity and activity of the underlying condition, a prognostic indicator and a determinant of health service use [3].

There are many drug options for pain treatment and the decision is taken based on the type and intensity of symptoms. However, the adverse effects of clinically used drugs may be pronounced
[4]. Thus, new therapeutic alternatives are required and plants can constitute a valuable source of products for this purpose [5].

Hypericum polyanthemum Klotzsch ex Reichardt is a species native to South Brazil that presents among its main active metabolites the benzopyran 6-isobutyryl-5,7-dimethoxy-2,2-dimethylbenzopyran (HP1; > Fig. 1) [6], which presents an antinociceptive effect in rodents [7]. Despite this activity, the low water solubility $(5 \mu \mathrm{g} / \mathrm{mL})$ of this compound constitutes an obstacle to further in vivo studies.

Regarding the administration route, oral delivery is the chief pathway of drug therapy because of safety, efficacy, and ready access with minimal discomfort for most patients when compared 


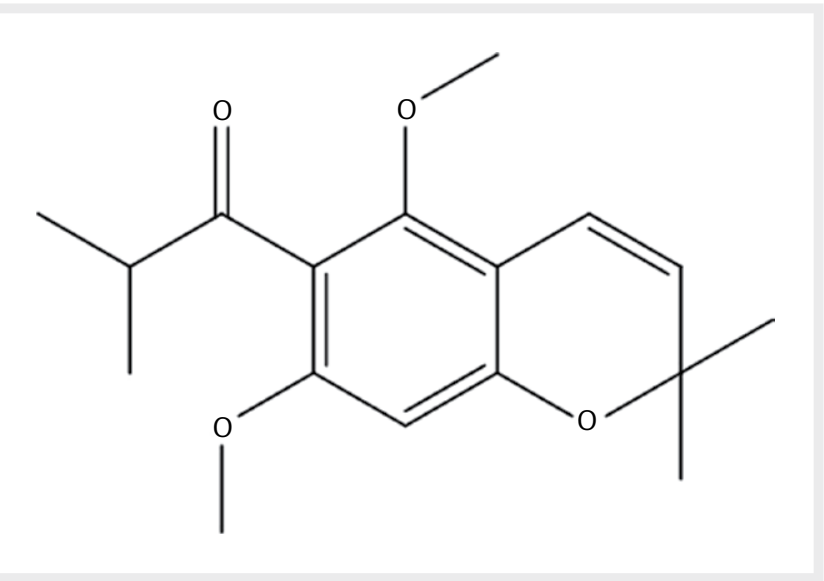

- Fig. 1 Chemical structure of benzopyran HP1.

with other routes [8]. To achieve systemic effects, drugs must reach the vascular system, which requires previous dissolution in the gastric juices of the stomach. However, given the low water solubility, the absorption of lipophilic compounds, such as HP1, by this route is frequently deficient. Beyond low solubility, many barriers can hamper the absorption of lipophilic compounds, such as limited absorption site, metabolizing intestinal enzymes, and the hepatic first-pass metabolism [9].

To overcome these drawbacks, lipophilic compounds have been incorporated in lipidic release systems [10], aiming at increasing solubility and improving biopharmaceutical aspects, such as intestinal permeability and bioavailability [11]. Among these systems, nanoemulsions have drawn attention because of their peculiar characteristics related to the small size of oil droplets. These systems show high stability and easiness of penetration in the intestinal mucosa, which enables them to act as excellent carrier systems for lipophilic compounds [12]. The literature presents many cases in which the incorporation of bioactive compounds within nanoemulsion systems improved biological activities, such as analgesic $[13,14]$, antihypertensive [15], and anticancer [16].

The aims of the present study were to incorporate the benzopyran HP1 in a triglyceride nanoemulsion and to verify the effect of nanoemulsification on the antinociceptive effect in mice via the hot plate test.

\section{Results and Discussion}

In this study, a nanoemulsion was prepared aiming at improving the antinociceptive effect of HP1, a natural benzopyran. The nanoemulsions were characterized in terms of droplet size and polydispersity index. The results ( $\triangleright$ Table 1 ) indicated that a spontaneous emulsification method generated monodisperse nanoemulsions (polydispersity index $<0.25$ ) with an average particle size of approximately $170 \mathrm{~nm}$. These data were consistent with those present in the morphological analysis by transmission electron microscopy (TEM; - Fig. 2). The photomicrographs revealed spherical structures with an average diameter between 100 and $200 \mathrm{~nm}$ and a defined interface without deposit of the compound, suggesting that HP1 was dispersed in the internal phase of the formulations.
- Table 1 Nanoemulsion characteristics.

\begin{tabular}{|c|c|c|c|}
\hline & $\Phi(\mathrm{nm})^{1}$ & PDI $^{2}$ & $\begin{array}{l}\text { Content } \\
\text { (mg/mL) }\end{array}$ \\
\hline $\mathrm{HP} 1(1.5 \mathrm{mg} / \mathrm{mL})$ & $169.65 \pm 1.32$ & $0.12 \pm 0.04$ & $1.46 \pm 0.01$ \\
\hline HP1 $(3.0 \mathrm{mg} / \mathrm{mL})$ & $174.00 \pm 6.98$ & $0.11 \pm 0.03$ & $2.94 \pm 0.01$ \\
\hline HP1 $(4.5 \mathrm{mg} / \mathrm{mL})$ & $164.43 \pm 0.83$ & $0.13 \pm 0.01$ & $4.28 \pm 0.01$ \\
\hline HP1 $(6.0 \mathrm{mg} / \mathrm{mL})$ & $159.30 \pm 4.30$ & $0.22 \pm 0.02^{* * *}$ & $5.99 \pm 0.12$ \\
\hline Blank & $168.06 \pm 10.98$ & $0.13 \pm 0.05$ & - \\
\hline \multicolumn{4}{|c|}{$\begin{array}{l}{ }^{1} \text { Droplet size; }{ }^{2} \text { polydispersity index. }{ }^{* * *} \text { Statistical difference by } \\
\text { one-way ANOVA followed by Tukey's test related to blank nanoemul- } \\
\text { sion at } p<0.001 \text {. }\end{array}$} \\
\hline
\end{tabular}

These results may be due to low HP1 water solubility because the HP1 partition coefficient octanol/water $\left(\log \mathrm{P}_{\mathrm{o} / \mathrm{w}}\right)$ was $4.3 \pm 0.39$, which is characteristic of lipophilic compounds. The solubility in the nanoemulsion oil core (medium-chain triglycerides) selected to prepare HP1-loaded nanoemulsions was also evaluated, and the value of $41.25 \pm 0.97 \mathrm{mg} / \mathrm{mL}$ was found, which is very high and promotes the compound solubilization within the oil core.

Regarding pharmacological outcomes, the current study confirms previous results by Haas et al. [7], who revealed a dose-dependent antinociceptive effect of HP1 mediated by the opioid system. This is in agreement with scientific evidences pointing to the promising pharmacological properties of the benzopyran skeleton [17-21]. Several molecules comprising this nucleus, natural or synthetic, have shown relevant pharmacological activities: tonabersat (SB-220453) - anticonvulsant [17]; 7-hydroxy-2H-1-benzopyran, -2,3-diaryl and halogenated benzopyrans - anti-inflammatory and antipyretic activities through cyclooxygenase inhibition [18]; cannabinoids - antinociceptive [19], antipsychotic [20], and psychotomimetic [21] effects.

Most important, our results demonstrated that the nanoemulsification was able to improve the HP1 antinociceptive effect. The active dose of HP1-loaded nanoemulsion was lower than the HP1free form dose at 60 min after treatment ( $\vee$ Fig. 3 ). The HP1-free form reached its maximal effect at $45 \mathrm{mg} / \mathrm{kg}$, whereas the HP1loaded nanoemulsion reached the same effect at $30 \mathrm{mg} / \mathrm{kg}$. Furthermore, the effect of the HP1-loaded nanoemulsion was long lasting. The HP1-free form lost its antinociceptive effect at $120 \mathrm{~min}$, while the HP1-loaded nanoemulsion maintained it until $180 \mathrm{~min}$. It is noteworthy that at 120 and $180 \mathrm{~min}$, the effect of the HP1loaded nanoemulsion was comparable to the morphine effect (॰ Fig. 4).

These findings could be attributable to the better compound solubilization when loaded in a nanoemulsion. The use of nanotechnology-based formulations as delivery systems is well documented in the literature. The analgesic compounds morphine [22] and acetylsalicylic acid [23] have already been incorporated in nanoemulsions to increase their absorption, and, thus, pharmacodynamic activity. Moreover, better oral absorption of several lipophilic compounds loaded in nanoemulsions has been demonstrated [24, 25].

Some physicochemical mechanisms have been proposed to describe the nanoemulsification's ability to improve the lipophilic compound absorption. The first explanation is that small negatively charged nanoparticles can pass through the mucosal layer of ep- 

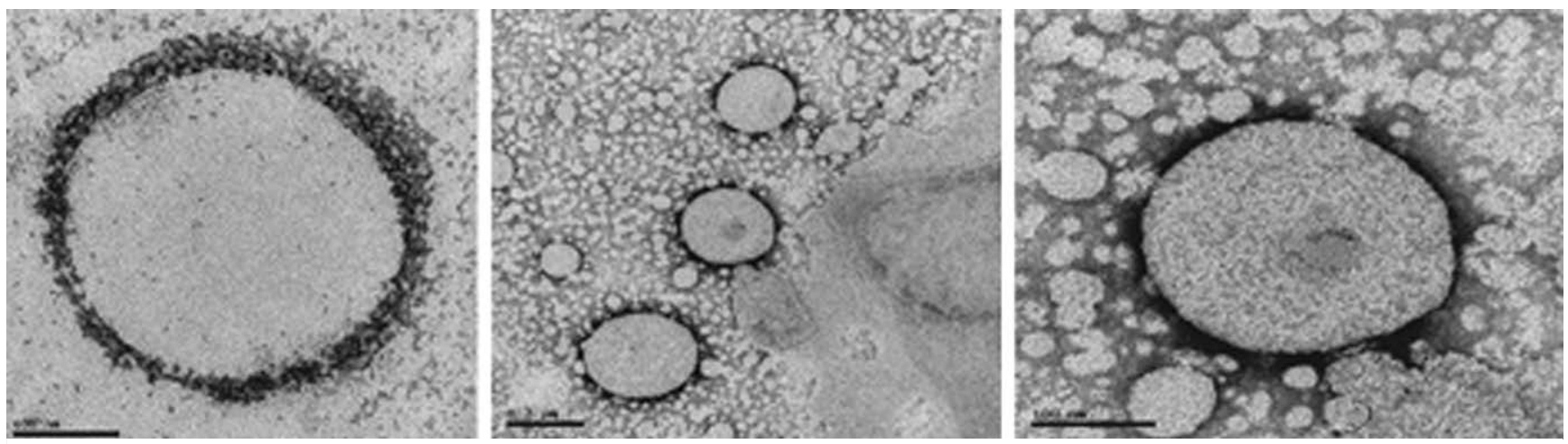

- Fig. 2 Nanoemulsion micrographs after HP1 incorporation (magnification $300000 \times$ ).

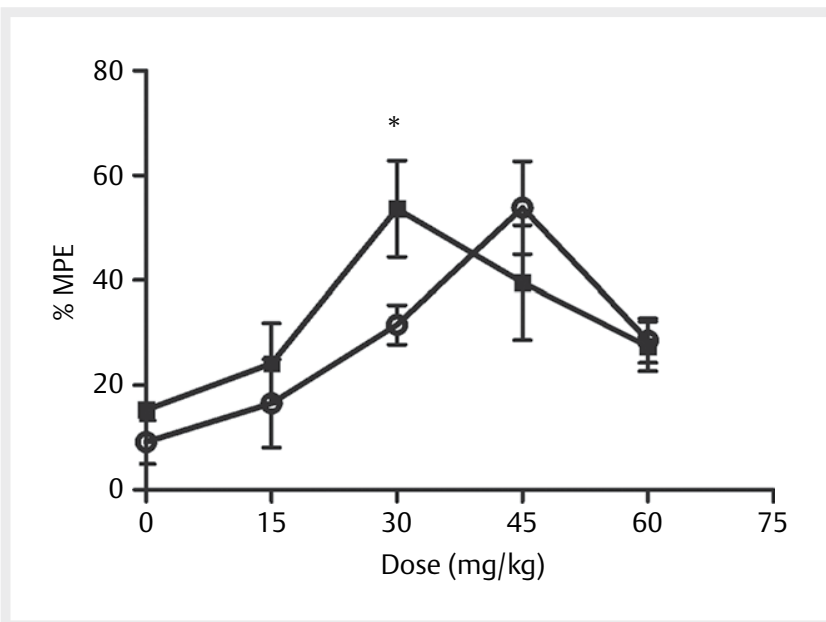

- Fig. 3 Dose-response curve of \% of the maximum possible antinociceptive effect (\%MPE) of HP1-free form (O) or loaded nanoemulsion $(\mathbf{\square})$. The results are presented as the mean \pm SEM $(n=9$ mice/group). Significantly different values were detected by one-way ANOVA followed by the Student-Newman-Keuls test. ${ }^{*} p<0.05$ compared with the HP1-free form at $45 \mathrm{mg} / \mathrm{kg}$.

ithelial cells and then be absorbed by the intestine [26]. Moreover, the lipid droplet surface area increases with the decrease in particle size, leading to an increase in lipid digestion by gastrointestinal enzymes [27]. In addition, the bioavailability of lipophilic compounds could be reduced when the lipidic phase consists of an indigestible lipid. In formulations with digestible lipids (like mediumchain triglycerides), the compound can be solubilized by micelles, mixed micelles, vesicles, and free fatty acids as a result of lipid digestion and, thus, be absorbed by intestinal cells [28]. Furthermore, the literature reports additional impacts of a lipophilic compound nanoemulsification, such as residence time increasing in the gastrointestinal tract, intestinal lymphatic pathway stimulus, intestinal permeability alteration, and reduction in the efflux transporters and metabolism activities [11].

Interestingly, both HP1-free form and loaded nanoemulsions displayed a bell-shaped dose-response. This HP1 pharmacological behavior has already been demonstrated by Haas et al. [7] and was also reported for some peculiar opioid analgesics, such as buprenorphine and its metabolite norbuprenorphine [29,30]. This

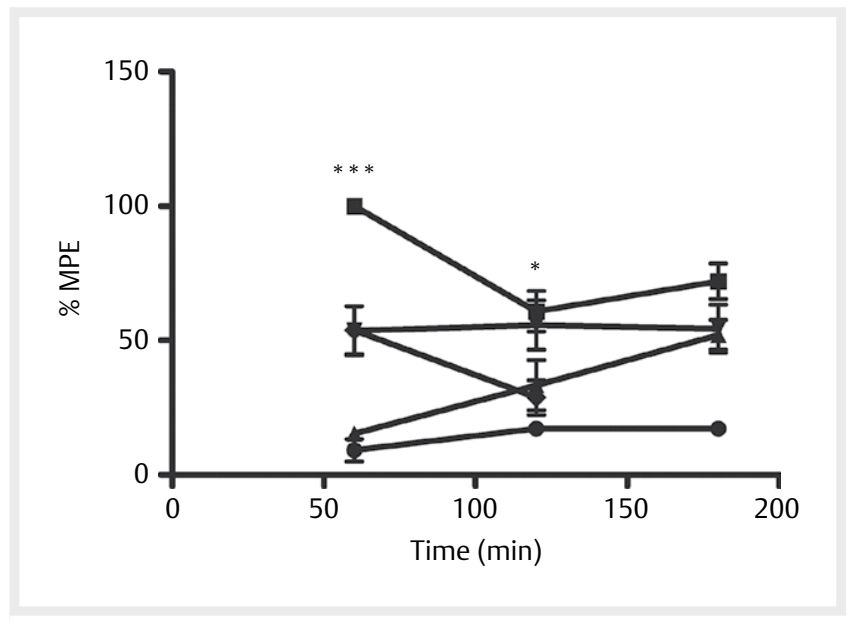

Fig. 4 Dose-response curve of \% of the maximum possible antinociceptive effect (\%MPE) of vehicle saline $(\bullet)$, morphine $(10 \mathrm{mg} /$ $\mathrm{kg})(\boldsymbol{\square})$, vehicle nanoemulsion $(\mathbf{\Delta})$, HP1-loaded nanoemulsion $30 \mathrm{mg} / \mathrm{kg}(\boldsymbol{\nabla})$, and HP1-free form $45 \mathrm{mg} / \mathrm{kg}(\downarrow)$. The results are presented as means \pm SEM ( $n=9$ mice/group). Significantly different values were detected by one-way ANOVA followed by the StudentNewman-Keuls test. ${ }^{* * *} \mathrm{p}<0.001$ vs. morphine and ${ }^{*} \mathrm{p}<0.05$ vs. saline vehicle.

behavior has been attributed to the $\mathrm{mu}(\mu)$ opioid receptor partial agonism [29] and interactions with supraspinal opioid-like receptors (ORL-1), which can induce a pro-nociceptive effect or, at least, oppose opioid receptor-mediated antinociception at higher doses [31]. Furthermore, buprenorphine also has the capacity of activating the delta $(\Delta)$ opioid receptor as an antagonist [32]. Therefore, the bell-shaped dose-response curve presented by HP1 might be due to interactions with different opioid receptors, as an agonist and/or antagonist. Further studies are necessary to confirm this hypothesis.

The antinociceptive doses of he HP1-free form $(45 \mathrm{mg} / \mathrm{kg})$ and loaded nanoemulsions $(30 \mathrm{mg} / \mathrm{kg}$ ) did not cause any motor impairment in animals as seen in the rotarod test $(60,120$, and $180 \mathrm{~min})$, which rules out the possibility that the animals' behavior in the hot plate are due to motor impairment or neurotoxicity (> Fig. 5).

Surprisingly, the blank nanoemulsion also exhibited antinociceptive effects at $180 \mathrm{~min}$ ( $\triangleright$ Fig. 4 ), which may contribute to the 
effect of the HP1-loaded nanoemulsion. The antinociceptive properties of blank nanostructured systems were already reported in acetic acid-induced abdominal constrictions and hot plate tests $[23,33]$. The nanoemulsion system used in the present study contains egg lecithin (2\%), which is composed of approximately $80 \%$ phosphatidylcholine. This composition could explain the observed effects since choline (a portion of phosphatidylcholine) is recognized by exhibiting antinociceptive effects mediated by the cholinergic system through $\alpha-7$ nicotinic acetylcholine receptor activation [34].

In summary, the results so far demonstrated that the nanoemulsion system improves the antinociceptive effect of HP1, a natural benzopyran, and also add evidence that blank nanostructured systems may present antinociceptive effects under certain conditions, which deserves further studies.

\section{Materials and Methods}

\section{Plant material}

Flowering aerial parts of $H$. polyanthemum were collected in Caçapava do Sul, Rio Grande do Sul state, Brazil, in September 2013. Plants were identified by Dr. Sérgio Bordignon (UNILASALLE, RS). Voucher specimens were deposited in the herbarium of Federal University Rio Grande do Sul (ICN) (Bordignon et al., 3118). Plant collection was authorized by IBAMA (Brazilian Institute of Ambient Media and Renewable Natural Resources; No. 003/2008, protocol: 02000.001717/1008-60).

\section{Extraction and isolation}

The dried and powdered plant material ( $500 \mathrm{~g}$ ) was successively extracted with $n$-hexane at room temperature (each solvent renewal $24 \mathrm{~h}$ ). The extracts were pooled and evaporated to dryness under reduced pressure, and the epicuticular waxes were removed by acetone treatment. This fraction was stored at $-20^{\circ} \mathrm{C}$ until the isolation process.

The acetone-soluble fraction was subjected to dry column vacuum chromatography (DCVC) on silica gel $60 \mathrm{GF}_{254}$ as the stationary phase and an $n$-hexane-dichloromethane (100:0 $\rightarrow$ 50:50) gradient as the mobile phase to obtain enriched fractions of HP1. Then, these fractions were submitted to centrifugal planar chromatography (CPC; Chromatotron, model 7924T, Harrison Research) on silica gel $60 \mathrm{GF}_{254}$ as the stationary phase and $n$-hexane-ethyl acetate $(100: 0 \rightarrow 50: 50)$ as the mobile phase to obtain the compound HP1.

The identity of HP1 was confirmed by nuclear magnetic resonance ( ${ }^{1} \mathrm{H}$ and ${ }^{13} \mathrm{C}$ NMR) and mass spectrometry (see Supporting Information). The spectra did not present any interfering signal, indicating the purity of the compound. These results were compared with previous data for the compound [6]. The purity was also confirmed by HPLC, presenting a peak area greater than $98 \%$, using a system composed of acetonitrile (60\%) and water (40\%) as the mobile phase and using a Waters Nova-Pack C18 column $(4 \mu \mathrm{m}$, $3.9 \mathrm{~mm} \times 150 \mathrm{~mm}$ ) adapted to a guard column Waters Nova-Pack C18 $60 \AA$ ( $3.9 \mathrm{~mm} \times 20 \mathrm{~mm})$. The flow rate was $1 \mathrm{~mL} / \mathrm{min}$ at $\lambda=230 \mathrm{~nm}$ at $25^{\circ} \mathrm{C}$.
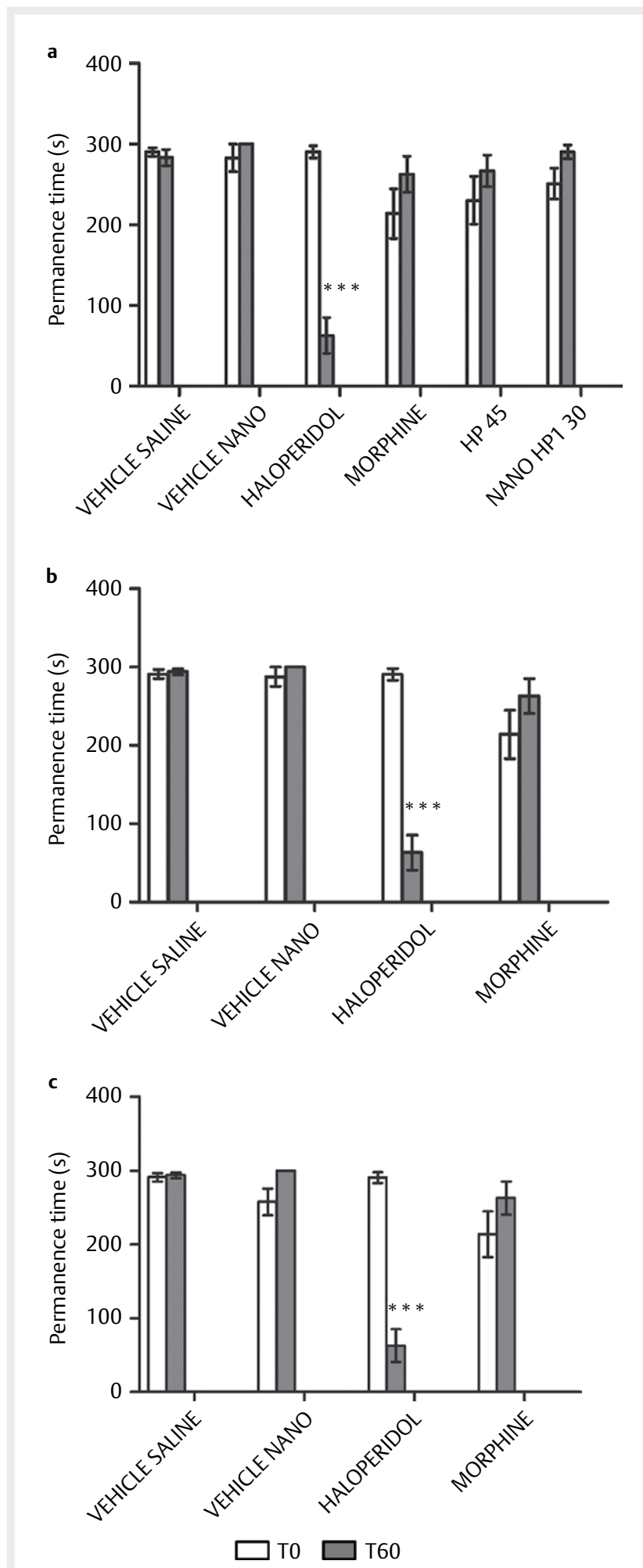

- Fig. 5 Effect of benzopyran HP1-free form $(45 \mathrm{mg} / \mathrm{kg})$ and loaded nanoemulsion $(30 \mathrm{mg} / \mathrm{kg}$ ), haloperidol ( $4 \mathrm{mg} / \mathrm{kg}$ as a positive control), and morphine (10 mg/kg as a positive control of antinociception) in a rotarod apparatus after $60 \mathrm{~min}$ a; controls haloperidol, morphine, and nanoemulsion after $120 \mathbf{b}$ and $180 \mathrm{~min} \mathbf{c}$. The results are presented as means \pm SEM ( $n=7$ mice/group). Significantly different values were detected by two-way repeated measures ANOVA followed by the Student-Newman-Keuls test. ${ }^{* * *} \mathrm{p}<0.001$ comparing $\mathrm{T}_{0}$ with $\mathrm{T}_{60}$. 


\section{Analytical methodology}

Prior to the preparation of HP1 nanoemulsions, the validation of an analytical method for determinations of HP1, employing an HPLC system, was carried out according to the International Conference on the Harmonization of Technical Requirements for the Registration of Pharmaceuticals for Human Use [35]. A linear response was obtained in the evaluated concentration range (1.99$125 \mu \mathrm{g} / \mathrm{mL}$ ), with a correlation coefficient of 0.999 . In addition, this method was shown to have a good precision (RSD $<0.91$ for repeatability and $<1.85$ for intermediate precision). The specificity was tested in the presence of other benzopyrans with a similar structure, with no interference in the HP1 analysis

\section{Characteristics of benzopyran HP1}

To evaluate the characteristics of water solubility, the partition coefficient $\left(\log \mathrm{P}_{\mathrm{o} / \mathrm{w}}\right)$ was determined with a computational software (ACD Labs Release 2012 - File ver. 14.1). After that, the compound solubility in the nanoemulsion oil core was assessed. For this purpose, an excess of HP1 was added to $500 \mu \mathrm{L}$ of medium-chain triglycerides (MCT), under agitation, for $24 \mathrm{~h}$. Then, the solutions were centrifuged and the supernatant was diluted with methanol (HPLC grade; 1:400). The samples were then evaluated by HPLC using the above-described method.

\section{Nanoemulsion preparation}

The nanoemulsions were prepared by a spontaneous emulsification method. The oil core [ $8 \%$ of MCT (Lipoid), $2 \%$ egg lecithin (Lipoid E-80) and HP1] and aqueous components ( $1 \%$ of polysorbate $80)$ were dissolved in an ethanol:acetone (1:1) mixture and ultrapure water, respectively. HP1 (1.5, 3.0, 4.5, and $6.0 \mathrm{mg} / \mathrm{mL})$ was added in increasing order of amount to the organic phase. This phase was slowly poured, under moderate magnetic stirring, on the aqueous phase. The solvent excess was eliminated under reduced pressure at $45^{\circ} \mathrm{C}$ until the final required volume was acquired $(5 \mathrm{~mL})$.

\section{Nanoemulsion characterization}

The nanoemulsions were characterized according to particle size and polydispersity index through dynamic light scattering, with a Malvern Zetasizer ZS (3000HS Zetasizer, Malvern Instruments). The results are expressed as the mean of three determinations of three different batches.

\section{Nanoemulsion morphology}

The nanoemulsions were visualized with transmission electron microscopy (JEOL JEM 1200 Exll) at $120 \mathrm{kV}$ voltage and $300000 \times$ magnification. After preparation, samples were deposited on copper metallic supports (200 mesh) and submitted to negative contrast with uranyl acetate solution (2\%). The samples were prepared $24 \mathrm{~h}$ before analysis and maintained in a desiccator.

\section{Animals}

Male CF1 mice (25-30 g) from the breeding colony of Federal University of Santa Maria were used. Before the experiments, the animals were housed in plastic cages of $17 \times 28 \times 13 \mathrm{~cm}, 6$ per cage, under a 12/12-h light/dark cycle (lights from 7:00 to 19:00 h) at a constant temperature $\left(23^{\circ} \mathrm{C} \pm 2{ }^{\circ} \mathrm{C}\right)$. The animals were kept in an exhaustion system (ventilated shelves; Alesco) with monitored humidity and free access to a standard certified rodent diet and tap water. The experiments were performed between 10:00 and 16:00 h, with $1 \mathrm{~h}$ of adaptation in the experimental room. Before administration by the oral route, the animals were made to fast for $2 \mathrm{~h}$. All protocols were approved by the local research ethical committee (UFRGS; no. 26390) and were in agreement with Brazilian law [36] and the Council for International Organization of Medical Sciences International (CIOMS) guiding principles for biomedical research involving animals [37].

\section{Drugs and treatments}

The following drugs were used: morphine (Cristália), prepared from a commercial product “Dimorf” (morphine sulfate $10 \mathrm{mg} / \mathrm{mL}$ ) and haloperidol (purity > 98\%; Sigma-Aldrich). HP1-free form was dissolved in a mixture of polysorbate $80(2 \%)$ and saline solution $(0.9 \%$ $\mathrm{NaCl}$ ) and the HP1-loaded nanoemulsion was directly administered. The control animals received a vehicle (saline solution with $2 \%$ of polysorbate 80 or blank nanoemulsion). The doses were chosen according to previous studies conducted by our group [7]. The sample size was determined as nine animals per group considering an $\alpha$ value of 0.01 and a test power of 0.9 .

\section{Hot plate test}

Initially, the mice were habituated to the nonfunctioning apparatus for $1 \mathrm{~min}$. Then, the animals were placed on the functioning hot plate (Ugo Basile) at $55 \pm 2{ }^{\circ} \mathrm{C}$ [38] to determine baseline responsiveness. The time past until the animal licked one of its hind paws or jumped was recorded in seconds (latency time). After that, the animals were withdrawn from the hot plate. Mice that presented baseline reactions of more than $20 \mathrm{~s}$ were eliminated from the experiment. Immediately, the selected animals received the different treatments and were exposed to the hot plate $1 \mathrm{~h}$ afterwards. The treatments were administered by gavage $(1 \mathrm{~mL} / 100 \mathrm{~g})$ at the following doses: HP1-free form (15, 30, 45 and $60 \mathrm{mg} / \mathrm{kg}$ ); HP1-loaded nanoemulsions (15, 30, 45 and $60 \mathrm{mg} / \mathrm{kg}$ ); vehicle control (saline added of $2 \%$ polysorbate 80 ); blank nanoemulsion and morphine as a positive control $(10 \mathrm{mg} / \mathrm{kg})$.

In order to verify the duration of the antinociceptive effect, different groups of mice treated with vehicle, morphine, HP1-free form $45 \mathrm{mg} / \mathrm{kg}$ or HP1-loaded nanoemulsions $30 \mathrm{mg} / \mathrm{kg}$ were evaluated in the hot plate test 120 and 180 min after treatment.

In the second hot plate session, a maximum latency time of $40 \mathrm{~s}$ was imposed to avoid tissue damage. The percentage of maximum possible antinociceptive effect (MPE) was calculated according to the following equation:

$\%$ MPE $=\frac{(\text { Post }- \text { drug latency }- \text { pre }- \text { drug latency }) \times 100}{(\text { Cut }- \text { off latency }- \text { pre }- \text { drug latency })}$

\section{Motor coordination test (rotarod)}

For the motor coordination test, the rotarod apparatus was used [39]. The apparatus consisted of a cylinder (3 cm in diameter) rotating at $5 \mathrm{rpm}$. One day before testing, the animals were trained once for $5 \mathrm{~min}$. On the test day, the mice were trained again for $5 \mathrm{~min}$ and those that were able to stay balanced for $90 \mathrm{~s}$ on the 
rotarod were selected for analysis. The selected mice received vehicle control, blank nanoemulsion, HP1-free form $(45 \mathrm{mg} / \mathrm{kg})$ and HP1-loaded nanoemulsion ( $30 \mathrm{mg} / \mathrm{kg}$ ), morphine $(10 \mathrm{mg} / \mathrm{kg}$ ) and haloperidol as a positive control $(4 \mathrm{mg} / \mathrm{kg})$. Pretreatment was immediately provided after the baseline responsiveness evaluation. Mice performance was measured at 60,120 , or 180 min after drug administration. The integrity of motor coordination was assessed on the basis of the longest time of permanence in a 5 -min period.

\section{Statistical analysis}

Data were analyzed by one-way analysis of variance (ANOVA) and two-way repeated-measures ANOVA, both followed by the Student-Newman-Keuls test. All results are expressed as means \pm SEMs. The analyses were performed using Sigma Stat software (ver. 2.03). Differences were considered statistically significant at $\mathrm{p}<0.05$.

\section{Acknowledgments}

Financial support by the Brazilian funding agencies (CAPES, CNPq, and FAPERGS) for part of this work is acknowledged. The manuscript was carefully reviewed by a language service, Enago, Crimson Interactive.

\section{Conflict of Interest}

The authors declare no conflict of interest.

\section{References}

[1] International Association for the Study of Pain (IASP). 2016;IASP taxonomy. Available at http://www.iasp-pain.org/Taxonomy\#Pain Accessed May 2, 2016

[2] Henschke N, Kamper S], Maher CG. The epidemiology and economic consequences of pain. Mayo Clin Proc 2015; 90: 139-147

[3] McBeth J, Jones K. Epidemiology of chronic musculoskeletal pain. Best Pract Res Clin Rheumatol 2007; 21: 403-425

[4] Woodcock J. A difficult balance-pain management, drug, safety, and the FDA. N Engl J Med 2009; 361: 2105-2107

[5] Dutra RC, Campos MM, Santos AR, Calixto JB. Medicinal plants in Brazil: Pharmacological studies, drug discovery, challenges and perspectives. Pharmacol Res 2016; 112: 4-29

[6] Ferraz AB, Bordignon SA, Staats C, Schripsema J, von Poser GL. Benzopyrans from Hypericum polyanthemum. Phytochemistry 2001; 57: $1227-1230$

[7] Haas JS, Viana AF, Heckler AP, von Poser GL, Rates SM. The antinociceptive effect of a benzopyran (HP1) isolated from Hypericum polyanthemum in mice hot-plate test is blocked by naloxone. Planta Med 2010; 76: 1419-1423

[8] Lennernäs H. Animal data: the contributions of the Ussing chamber and perfusion systems to predicting human oral drug delivery in vivo. Adv Drug Deliv Rev 2007; 59: 1103-1120

[9] Dahan A, Hoffman A. Enhanced gastrointestinal absorption of lipophilic drugs. In: Touitou E, Barry BW. ed. Enhancement in drug delivery. New York: CRC Press; 2007: 11-31

[10] Pouton CW. Formulation of poorly water-soluble drugs for oral administration: physicochemical and physiological issues and the lipid formulation classification system. Eur J Pharm Sci 2006; 29: 278-287
[11] Kotta S, Khan AW, Pramod K, Ansari SH, Sharma RK, Ali ]. Exploring oral nanoemulsions for biovaliability enhancement of poorly water-soluble drugs. Expert Opin Drug Deliv 2012; 9: 585-598

[12] Rajpoot P, Pathak K, Bali V. Therapeutic applications of nanoemulsion based drug delivery systems: A review of patents in last two decades. Recent Pat Drug Deliv Formul 2011; 5: 163-172

[13] Tang SY, Sivakumar M. Design and evaluation of aspirin-loaded water-in-oil-in-water submicron multiple emulsions generated using two-stage ultrasonic cavitational emulsification technique. Asia-Pac J Chem Eng 2012; 7: S145-S156

[14] Tang SY, Sivakumar M, Nashiru B. Impact of osmotic pressure and gelling in the generation of highly stable single core water-in-oil-inwater (W/O/W) nano multiple emulsions of aspirin assisted by two-stage ultrasonic cavitational emulsification. Colloids Surf B Biointerfaces 2013; 102: 653-658

[15] Gorain B, Choudhury H, Kundu A, Sarkar L, Karmakar S, Jaisankar P, Pal TK. Nanoemulsion strategy for olmesartan medoxomil improves oral absorption and extended antihypertensive activity in hypertensive rats. Colloids Surf B Biointerfaces 2014; 115: 286-294

[16] Ganta S, Devalapally H, Amiji M. Curcumin enhances oral bioavailability and anti-tumor therapeutic efficacy of paclitaxel upon administration in nanoemulsion formulation. J Pharm Sci 2010; 99: 4630-4641

[17] Parsons AA, Bingham S, Raval P, Read S, Thompson M, Upton N. Tonabersat (SB-220453) a novel benzopyran with anticonvulsant properties attenuates trigeminal nerve-induced neurovascular reflexes. Br J Pharmacol 2001; 132: 1549-1557

[18] Prasanna S, Manivannan E, Chaturvedi SC. Quantitative structureactivity relationship analysis of a series of 2,3-diaryl benzopyran analogues as novel selective cyclooxygenase- 2 inhibitors. Bioorg Med Chem Lett 2004; 14: 4005-4011

[19] Welch SP. Interaction of the cannabinoid and opioid systems in the modulation of nociception. Int Rev Psychiatry 2009; 21: 143-151

[20] Iseger TA, Bossong MG. A systematic review of the antipsychotic properties of cannabidiol in humans. Schizophr Res 2015; 162: 152-161

[21] Radhakrishnan R, Wilkinson ST, D'Souza DC. Gone to pot - a review of the association between Cannabis and psychosis. Front Psychiatry 2014; 5: 54

[22] Wang J], Hung CF, Yeh CH, Fang JY. The release and analgesic activities of morphine and its ester prodrug, morphine propionate, formulated by water-in-oil nanoemulsions. J Drug Target 2008; 16: 294-301

[23] Tang SY, Sivakumar M, Ng AM, Shridharan P. Anti-inflammatory and analgesic activity of novel oral aspirin-loaded nanoemulsion and nano multiple emulsion formulations generated using ultrasound cavitation. Int J Pharm 2012; 430: 299-306

[24] Parveen R, Baboota S, Ali J, Ahuja A, Vasudev SS, Ahmad S. Effects of silymarin nanoemulsion against carbon tetrachloride-induced hepatic damage. Arch Pharm Res 2011; 34: 767-774

[25] Oehlke K, Adamiuk M, Behsnilian D, Gräf V, Mayer-Miebach E, Walz E, Greiner R. Potential bioavailability enhancement of bioactive compounds using food-grade engineered nanomaterials: A review of the existing evidence. Food Funct 2014; 5: 1341-1359

[26] Cone RA. Barrier properties of mucus. Adv Drug Deliv Rev 2009; 61: 75-85

[27] Li Y, Hu M, McClements DJ. Factors affecting lipase digestibility of emulsified lipids using an in vitro digestion model: proposal for a standardised pH-stat method. Food Chem 2011; 126: 498-505

[28] Chakraborty S, Shukla D, Mishra B, Singh S. Lipid-an emerging platform for oral delivery of drugs with poor bioavailability. Eur J Pharm Biopharm 2009; 73: 1-15 
[29] Martin WR, Eades CG, Thompson JA, Huppler RE, Gilbert PE. The effects of morphine- and nalorphine-like drugs in the nondependent and morphine-dependent chronic spinal dog. J Pharmacol Exp Ther 1976; 197: 517-553

[30] Huang P, Kehner GB, Cowan A, Liu-Chen LY. Comparison of pharmacological activities of buprenorphine and norbuprenorphine: norbuprenorphine is a potent opioid agonist. J Pharmacol Exp Ther 2001; 297: 688-695

[31] Mogil JS, Pasternak GW. The molecular and behavioral pharmacology of the orphanin FQ/nociceptin peptide and receptor family. Pharmacol Rev 2001; 53: 381-415

[32] Sadée W, Rosenbaum JS, Herz A. Buprenorphine: Differential interaction with opiate receptor subtypes in vivo. J Pharmacol Exp Ther 1982; 223: 157-162

[33] Ferreira LM, Sari MHM, Cervi VF, Gehrcke M, Barbieri AV, Zborowski VA, Beck RCR, Nogueira CW, Cruz L. Pomegranate seed oil nanoemulsions improve the photostability and in vivo antinociceptive effect of a non-steroidal anti-inflammatory drug. Colloids Surf B Biointerfaces 2016; 144: 214-221

[34] Uteshev VV, Meyer EM, Papke RL. Regulation of neuronal function by choline and 4OH-GTS-2 through alpha-7 nicotinic receptors. J Neurophysiol 2003; 89: 1797-1806
[35] International conference on harmonisation of technical requirements for registration of pharmaceuticals for human use (ICH). Validation of analytical procedures: text and methodology Q2(R1). 1996. https:// www.ich.org/fileadmin/Public_Web_Site/ICH_Products/Guidelines/ Quality/Q2_R1/Step4/Q2_R1_Guideline.pdf. Accessed January 10, 2016

[36] Brasil CN. 2008;Lei procedimentos para o uso científico de animais. Lei n. 11794, Diário Oficial da União (DOU): Available at http://www. planalto.gov.br/ccivil_03/_ato2007-2010/2008/lei/111794.htm Accessed December 22, 2016

[37] Council for International Organization of Medical Sciences and the International Council for Laboratory Animal Science. Guiding principles for biomedical research involving animals. 2012. Available at http:// www.cioms.ch/index.php/12-newsflash/326-cioms-and-iclas-releasethe-new-international-guiding-principles-for-biomedical-research involving-animals. Accessed January 11, 2017

[38] Amresh G, Singh PN, Rao CH. Antinociceptive and antiarthritic activity of Cissampelos pareira roots. J Ethnopharmacol 2007; 111: 531-536

[39] Neves G, Menegatti R, Antonio CB, Grazziotin LR, Vieira RO, Rates SM, Noël F, Barreiro EJ, Fraga CA. Searching for multi-target antipsychotics: Discovery of orally active heterocyclic $\mathrm{N}$-phenylpiperazine ligands of D2-like and 5-HT1A receptors. Bioorg Med Chem 2010; 18: 19251935 